\title{
Effect of cerium addition on microstructures of carbon-alloyed iron aluminides
}

\author{
S SRIRAM, R BALASUBRAMANIAM*, M N MUNGOLE, S BHARAGAVA and \\ R G BALIGIDAD ${ }^{\dagger}$ \\ Department of Materials and Metallurgical Engineering, Indian Institute of Technology, Kanpur 208 016, India \\ ${ }^{\dagger}$ Defence Metallurgical Research Laboratory, Hyderabad 500 058, India
}

MS received 19 January 2004; revised 21 July 2005

\begin{abstract}
The effect of $\mathrm{Ce}$ addition on the microstructure of carbon-alloyed $\mathrm{Fe}_{3} \mathrm{Al}$-based intermetallic has been studied. Three different alloys of composition, Fe-18.5Al-3.6C, Fe-20.0Al-2.0C and Fe-19.2Al-3.3C$0.07 \mathrm{Ce}$ (in at \%), were prepared by electroslag remelting process. Their microstructures were characterized using optical and scanning electron microscopies. Stereological methods were utilized to understand the observed microstructures. All the alloys exhibited a typical two-phase microstructure consisting of $\mathrm{Fe}_{3} \mathrm{AlC}$ carbides in an iron aluminide matrix. In the alloy without Ce addition, large bulky carbides were equally distributed throughout the matrix with many smaller precipitates interspersed in between. In the alloy with Ce addition, the carbide grain sizes were finer and uniformly distributed throughout the matrix. The effect of Ce addition on the carbide morphology has been explained based on the known effect of Ce in modifying carbide morphology in cast irons.
\end{abstract}

Keywords. Iron aluminide; $\mathrm{Fe}_{3} \mathrm{Al}$; Ce addition; microstructure; stereology.

\section{Introduction}

Iron aluminides, based around the stoichiometric compositions, $\mathrm{Fe}_{3} \mathrm{Al}$ and $\mathrm{FeAl}$, offer excellent resistance to oxidation and sulphidation at high temperatures, with low material cost and density than austenitic and ferritic stainless steels (Liu et al 1990a; Liu and Kumar 1993). They contain enough aluminium to form a thin film of aluminium oxide (in oxidizing environments) that is often compact and protective. They possess relatively high specific strengths and suitable mechanical properties at elevated temperatures. They have, therefore, undergone extensive development, in the recent past, exclusively for high temperature applications. However, their potential use as structural materials at elevated temperatures has been hindered by limited ductility at room temperature and sharp drop in strength above $600^{\circ} \mathrm{C}$. It is well established that the poor room temperature ductility of iron aluminides is due to hydrogen embrittlement (Liu et al 1990b, 1996), with hydrogen causing embrittlement arising out of the interaction of atmospheric moisture with $\mathrm{Al}$ as per $2 \mathrm{Al}+3 \mathrm{H}_{2} \mathrm{O} \rightarrow \mathrm{Al}_{2} \mathrm{O}_{3}+6 \mathrm{H}$ (Zhu et al 1996). Considerable efforts have been put to understand and improve their mechanical properties. Addition of passivity-inducing alloying elements has been one of the methods suggested to improve ductility of iron aluminides (McKamey and Liu 1992; Balasubramaniam 1996, 1997). These alloying

*Author for correspondence (bala@iitk.ac.in) additions modify surface condition such that hydrogen diffusion into the material is hindered, thereby reducing the propensity to hydrogen embrittlement. Microstructural control leads to further enhancement in ductilities. These include refinement of grain structure, enhancement of grain boundary cohesion, control of grain shape and adjusting the recrystallization condition (McKamey and Pierce 1993; Lin et al 1994).

It has also been shown recently that carbon additions may be beneficial in improving the room temperature ductility of iron aluminides (Baligidad et al 1997a,b). The main benefit of carbon-alloyed iron aluminide is its cheap cost (by using steel scrap) and its robust processing by the electroslag remelting (ESR) process (Baligidad et al 1994). The addition of carbon even in small amounts, however, drastically modifies the microstructure because carbon results in the precipitation of $\mathrm{Fe}_{3} \mathrm{Al}_{x} \mathrm{C}_{y}$ carbides in the microstructure (Baligidad et al 1997a,b). The size, shape and distribution of these carbides are influenced by alloy composition and thermomechanical processing conditions (Baligidad and Radhakrishna 2000). Improvements in ductility have also been observed in carbon-alloyed aluminides and it has been suggested that carbon additions lowered the degree of hydrogen embrittlement by hindering hydrogen diffusion due to precipitated carbide (Sen and Balasubramaniam 2000) as well as interstitial carbon (Prakash and Sauthoff 2001). Lower hydrogen diffusivities have, in fact, been measured in carbon alloyed iron aluminides (Parvathavarthini et al 2002). 
Yangshan et al (1995) reported that small addition of $\mathrm{Ce}$ to $\mathrm{Fe}_{3} \mathrm{Al}$-based alloys enhanced ductility and strength of Cr-alloyed iron aluminides at ambient temperature. Moreover, they also observed improvements in tensile properties and creep resistance at $600^{\circ} \mathrm{C}$. Improvements were also observed in the case of $\mathrm{Ce}$ addition along with molybdenum, zirconium and niobium in iron aluminides. Ce addition resulted in a finer grain size material.

The aim of the present study was to understand the effect of $\mathrm{Ce}$ addition on the microstructure of carbonalloyed iron aluminides. The microstructures were analysed by stereological methods (Underwood 1970). Quantitative stereology is efficient in finding means for measuring familiar geometric quantities as well as discovering parameters that can be useful in establishing geometric relationships among the properties of alloys.

\section{Experimental}

The nominal compositions of alloys used in the present study, in atomic percent, were $\mathrm{Fe}-20 \cdot 0 \mathrm{Al}-2 \cdot 0 \mathrm{C}$, Fe$18 \cdot 5 \mathrm{Al}-3 \cdot 6 \mathrm{C}$ and $\mathrm{Fe}-19 \cdot 2 \mathrm{Al}-3 \cdot 3 \mathrm{C}-0 \cdot 07 \mathrm{Ce}$. The compositions of these alloys, in weight percent, were $\mathrm{Fe}-11.0 \mathrm{Al}-$ $0 \cdot 5 \mathrm{C}, \mathrm{Fe}-10 \cdot 5 \mathrm{Al}-0.9 \mathrm{C}$ and $\mathrm{Fe}-10 \cdot 5 \mathrm{Al}-0 \cdot 8 \mathrm{C}-0 \cdot 2 \mathrm{Ce}$, respectively. The iron aluminides were melted in a medium frequency air induction furnace of $50 \mathrm{~kg}$ capacity and chill cast into cast iron moulds. The air induction melted ingots (55 $\mathrm{mm}$ diameter, $360 \mathrm{~mm}$ long) were machined to $50 \mathrm{~mm}$ diameter for refining in an a.c. electro slag remelting (ESR) furnace of $350 \mathrm{kVA}$ capacity. A commercial prefused flux based on $\mathrm{CaF}_{2}\left(70 \% \mathrm{CaF}_{2}+15 \% \mathrm{CaO}+\right.$ $15 \% \mathrm{Al}_{2} \mathrm{O}_{3}$ ) was used. The flux was preheated and held at $850^{\circ} \mathrm{C}$ for $2 \mathrm{~h}$ before use to remove moisture. The iron aluminide electrode was remelted under this flux cover and cast into $76 \mathrm{~mm}$ ingot in a water cooled steel mould. Towards the end of the process, the power supply was gradually reduced to achieve hot tapping. Further details on process parameters and mechanical properties of iron aluminides can be found elsewhere (Baligidad et al 1994). The ingots were then forged to a reduction ratio of $70 \%$.

Specimens for microstructural studies were cut from the forged strips using a high speed abrasive silicon carbide cut-off wheel. The as-received microstructures in all the three sections (rolling (RD), long transverse (LT) and short transverse (ST)) were obtained by etching the polished surfaces (final polish with $1 \mu \mathrm{m}$ diamond paste) using $\quad 33 \% \mathrm{CH}_{3} \mathrm{COOH}+33 \% \mathrm{HNO}_{3}+1 \% \mathrm{HF}+33 \% \mathrm{H}_{2} \mathrm{O}$ (by volume). Microstructures were examined in all the three directions using an optical microscope (Axiolab A, Ziess, Germany) and a scanning electron microscope, SEM (JEOL JSM 840A).

Stereological analysis was performed using an image analysis software (Image-Pro Plus, version 4.1, Media Cybernetics, USA). The rolling plane was analysed in the stereological studies because the available area for analy- sis was larger for the rolling plane. Each sample was observed at 30 different locations (fields of view). The 95\% confidence interval, which is a measure of the sampling error, has also been estimated.

In order to estimate the volume fraction, $V_{\mathrm{V}}$, of the carbides, a $10 \times 10$ grid was used and the sample was observed at $500 \mathrm{x}$. The total number of intersection points between the crossed grid of the test lines and the carbides in each field of view were calculated manually and divided by the total number of points. The result provided the volume fraction. The size of the grains were calculated by imposing 8 random test lines, each of length $2300 \mu \mathrm{m}$, on the image taken at a magnification of $50 \times$. The total number of intersection points between the test lines and the grain boundaries was counted and the measured grain size is given by

$$
G z=(n L / P),
$$

where $G z$ represents the grain size, $n$ the total number of grid lines, $L$ the length of a grid line and $P$ the number of intersection points between the test lines and grain boundaries.

Surface area of exploded carbides per unit volume provides an understanding of the space occupied by the carbides in the matrix (Underwood 1970). For the purpose of calculating the surface area of the exploded carbides per unit volume and the contiguity parameters (to be discussed below), 10 test lines, each of length $206 \mu \mathrm{m}$, were drawn on the optical micrograph and the readings taken. The surface area of exploded carbides per unit volume is given by the relation

$$
\left(S_{\mathrm{V}}\right)_{\mathrm{C}}=(2 P / L),
$$

where $\left(S_{\mathrm{V}}\right)_{\mathrm{C}}$ is the surface area of the exploded carbides per unit volume, $P$ the number of intersection points between the test lines and the partition line of carbides, and $L$ the total length of the test lines. During the calculation of $\left(S_{\mathrm{V}}\right)_{\mathrm{G}}, 2$ is multiplied with $P$ because when a test line intersects the boundary of two grains, the number of intersection points were counted as one.

Contiguity is a measure of the fractional surface area of each feature occupied by other features of the same type (Underwood 1970). Contiguity of carbides is calculated using the equation

$$
C_{\mathrm{G}}=4 P_{L \alpha \alpha} /\left(4 P_{L \alpha \alpha}+2 P_{L \alpha \beta}\right)
$$

where $C_{\mathrm{G}}$ is the contiguity of carbides, $P_{L \alpha \alpha}$ the number of intersection points between the test lines and the partition line of two adjoining carbides divided by the unit length of the test line and $P_{L \alpha \beta}$ the number of point intersections between the test lines and the partition line of grains and carbides divided by the unit length of the test line.

\section{Results and discussion}

The microstructures of the as-received iron aluminide alloys were analysed in all the three directions. The opti- 
cal micrographs of $\mathrm{Fe}-18 \cdot 5 \mathrm{Al}-3.6 \mathrm{C}$ obtained from the rolling plane, longitudinal and short transverse sections of the as received plate are given in figure 1 , while the scanning electron micrographs for the same are provided in figure 2. In a similar fashion the optical and scanning electron micrographs for $\mathrm{Fe}-20 \cdot 0 \mathrm{Al}-2 \cdot 0 \mathrm{C}$ are presented in figures 3 and 4 , respectively, while those for $\mathrm{Fe}-$ 19.2Al-3.3C-0.07Ce in figures 5 and 6, respectively. All the alloys possessed recrystallized grains. This was expected because the thermomechanical processing of the alloys was performed at a high temperature $\left(550-600^{\circ} \mathrm{C}\right)$ where dynamic recrystallization had taken place (Baligidad et al 1997a,b).

The alloy, Fe-18.5Al-3.6C, exhibited a typical twophase structure (figures 1 and 2) consisting of carbides dispersed in the iron aluminide matrix. According to Baligidad et al $(1997 \mathrm{a}, \mathrm{b})$, the matrix phase is based on $\mathrm{Fe}_{3} \mathrm{Al}$ and the precipitates are $\mathrm{Fe}_{4-y} \mathrm{Al}_{y} \mathrm{C}_{x}$ carbides possessing perovskite structure. The carbides were distributed uniformly throughout the matrix of iron aluminide. The compositional analysis of the matrix for a alloy of similar composition revealed, for these category of alloys, the atomic ratio of iron and aluminium in the matrix, in the order of $3: 1$, thereby suggesting that the stoichiometric formula of the matrix phase as $\mathrm{Fe}_{3} \mathrm{Al}$ (Laha et al 2004). XRD studies conducted on the present alloys confirmed the formation of $\mathrm{Fe}_{3} \mathrm{AlC}$ carbides.

The carbides seen in the alloy, $\mathrm{Fe}-18 \cdot 5 \mathrm{Al}-3.6 \mathrm{C}$, on the rolling and longitudinal planes were of two distinct sizes. Larger bulky carbides were equally distributed throughout the matrix with many smaller precipitates interspersed in between (figure 1). The situation was similar in all the observed planes (figures 1a through 1c). However, the distribution of carbides in short transverse section (figure 1c) was slightly different in that the bulky carbides were smaller in size compared to that seen in other planes and were more closely spaced. Smaller precipitates were dispersed around the bulky carbides in a similar fashion to that seen in the other planes. This resulted due to thermomechanical processing.

In the case of $\mathrm{Fe}-20 \cdot 0 \mathrm{Al}-2 \cdot 0 \mathrm{C}$ alloy, similar bulky carbides were observed in the rolling, long transverse and short transverse planes (figures 3 and 4). Similarly, the smaller nodular precipitates were distributed around the bulky carbides. The distribution of carbides was uniform throughout the matrix. The carbon content in Fe-20.0Al$2.0 \mathrm{C}$ was lower than in $\mathrm{Fe}-18.5 \mathrm{Al}-3.6 \mathrm{C}$. This resulted in higher volume fraction of carbide and lower spacing between the bulky carbides in the latter alloy. In all the cross sections of $\mathrm{Fe}-20 \cdot 0 \mathrm{Al}-2 \cdot 0 \mathrm{C}$, the inter-carbide spacing was higher when compared to the $\mathrm{Fe}-18.5 \mathrm{Al}-3 \cdot 6 \mathrm{C}$ alloy. Examination of these microstructures using stereological methods confirmed that the volume fraction and the exploded surface area per unit volume of the carbides in the alloy $\mathrm{Fe}-18.5 \mathrm{Al}-3.6 \mathrm{C}$ was higher than the alloy $\mathrm{Fe}-20 \cdot 0 \mathrm{Al}-2 \cdot 0 \mathrm{C}$ (to be discussed below).
The addition of Ce modified the morphology of carbides (figures 5 and 6 ). The carbide grain sizes were finer and, moreover, the carbides were uniformly distributed throughout the matrix. Therefore, addition of Ce to iron aluminides affected the morphology and size of the carbides.
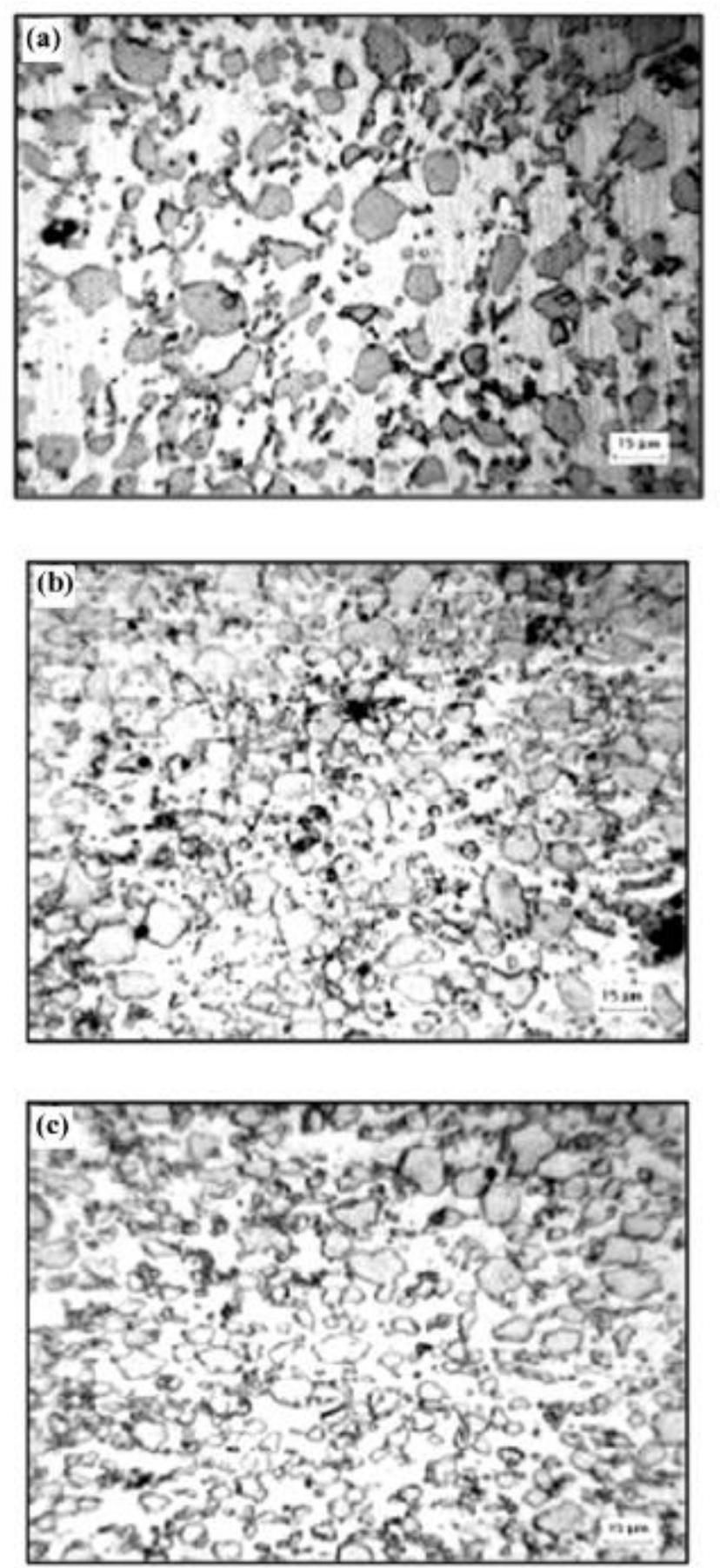

Figure 1. Optical micrographs of $\mathrm{Fe}-18 \cdot 5 \mathrm{Al}-3 \cdot 6 \mathrm{C}$ alloy in the (a) rolling plane, (b) long transverse, and (c) short transverse directions. 
The differences in carbide morphologies in the three iron aluminides under study were clearly revealed at higher magnifications in the SEM (figure 7).

The microstructures were analysed for obtaining information on the carbide particle distribution (the carbide particle size and its surface area per unit volume). The
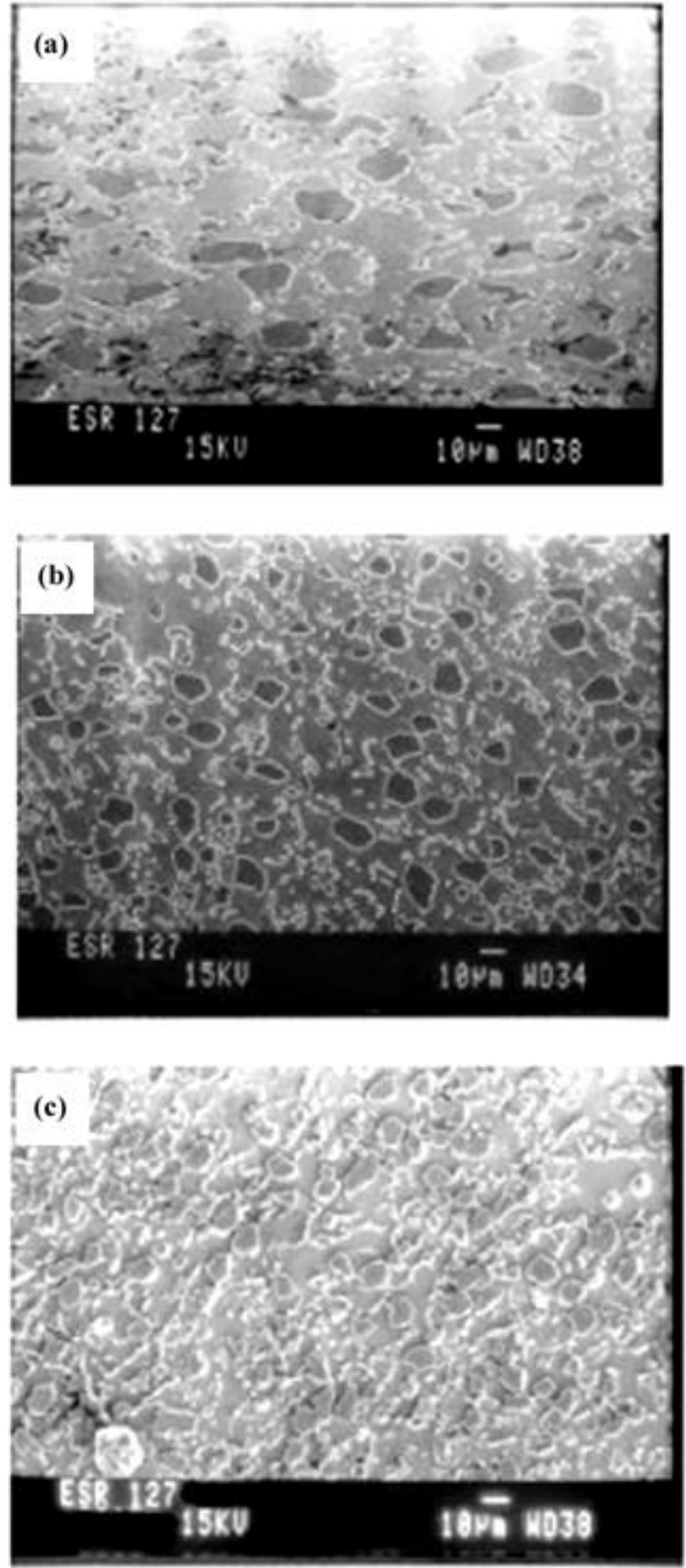

Figure 2. Scanning electron micrographs of Fe-18.5Al-3.6C alloy in (a) the rolling plane, (b) long transverse, and (c) short transverse directions. grain size and the mean volume fraction $\left(\bar{V}_{\mathrm{V}}\right)$ of the bulky carbides in the three alloys are reported in table 1 . It was not possible to reveal the grain boundaries in the microstructure of $\mathrm{Fe}-19 \cdot 2 \mathrm{Al}-3 \cdot 3 \mathrm{C}-0 \cdot 07 \mathrm{Ce}$ by etching. The surface area of exploded features per unit volume $\left(S_{\mathrm{V}}\right)$ and the contiguity for the bulky carbides are
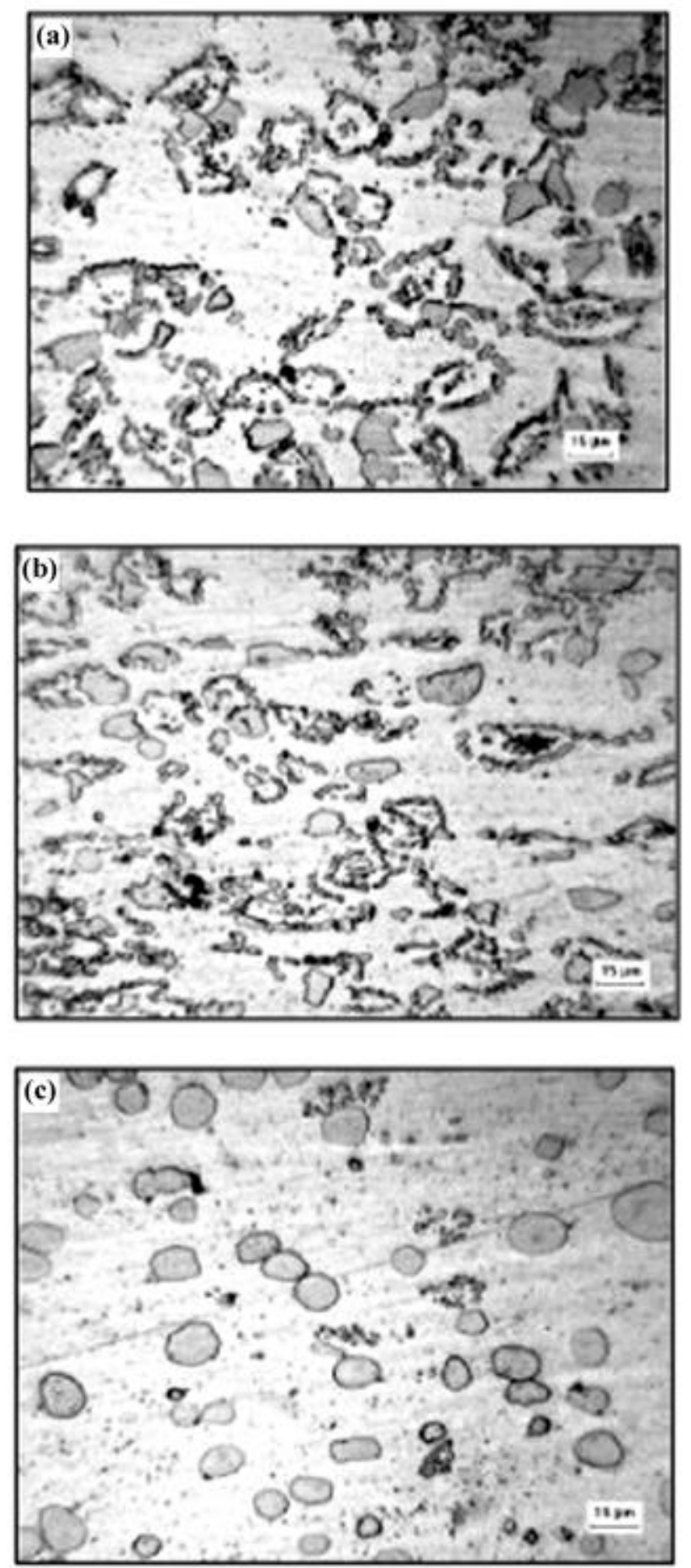

Figure 3. Optical micrographs of $\mathrm{Fe}-20 \cdot 0 \mathrm{Al}-2 \cdot 0 \mathrm{C}$ alloy in the (a) rolling plane, (b) long transverse, and (c) short transverse directions. 
presented in table 2 . The $95 \%$ confidence interval, which is a measure of the sampling error, is provided besides the individual measurements. As the $\mathrm{Fe}-18 \cdot 5 \mathrm{Al}-3.6 \mathrm{C}$ and $\mathrm{Fe}-19 \cdot 2 \mathrm{Al}-3 \cdot 3 \mathrm{C}-0 \cdot 07 \mathrm{Ce}$ alloys possessed higher carbon
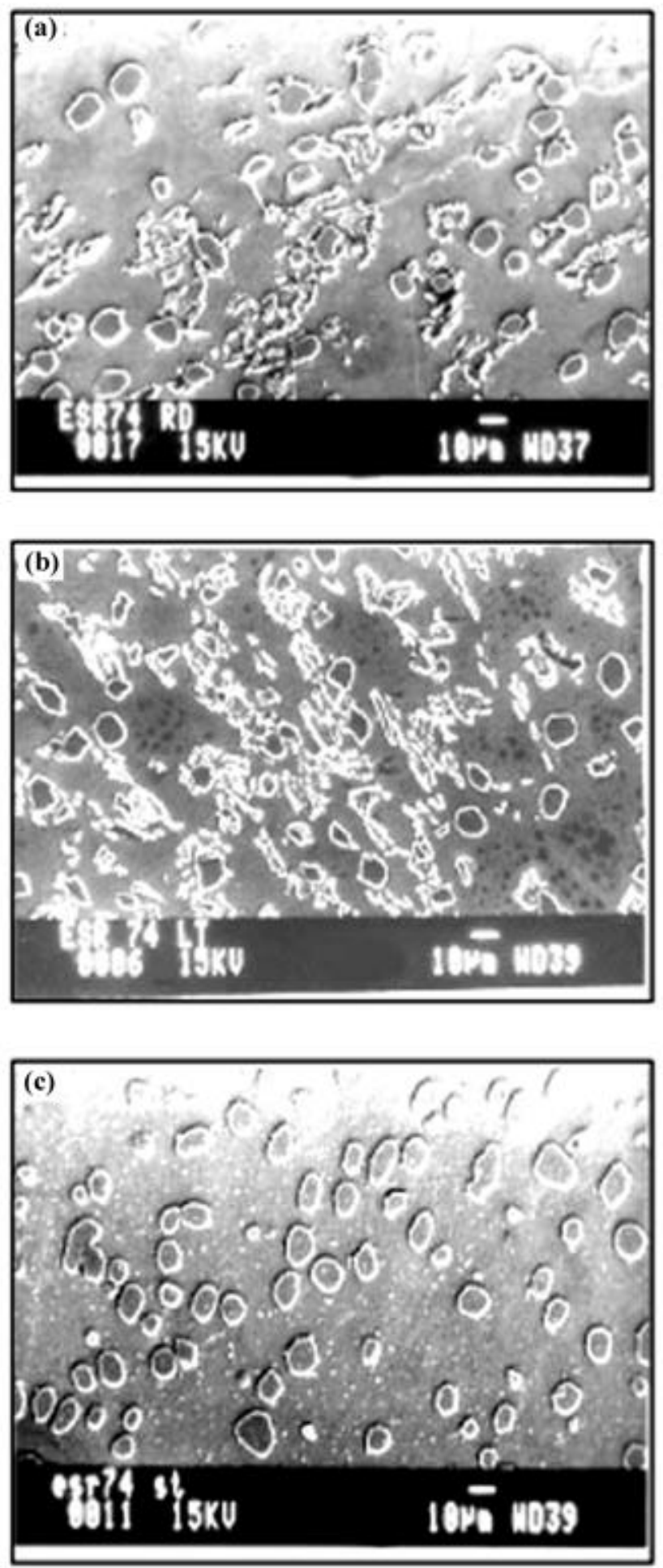

Figure 4. Scanning electron micrographs of Fe-20.0Al-2.0C alloy in the (a) rolling plane, (b) long transverse, and (c) short transverse directions. content than Fe-20.0Al-2.0C, these alloys exhibited a higher exploded surface area per unit volume of the carbide particles. The small-sized carbides of all the samples were uniformly distributed. Noticeable differences were observed only in the shape and size of the bulky carbides. Therefore, in estimating the above parameters, the finer particles of the carbides were neglected and the analysis was performed on bulky carbides. This provided a qualitative picture of the distribution of the larger carbide particles.
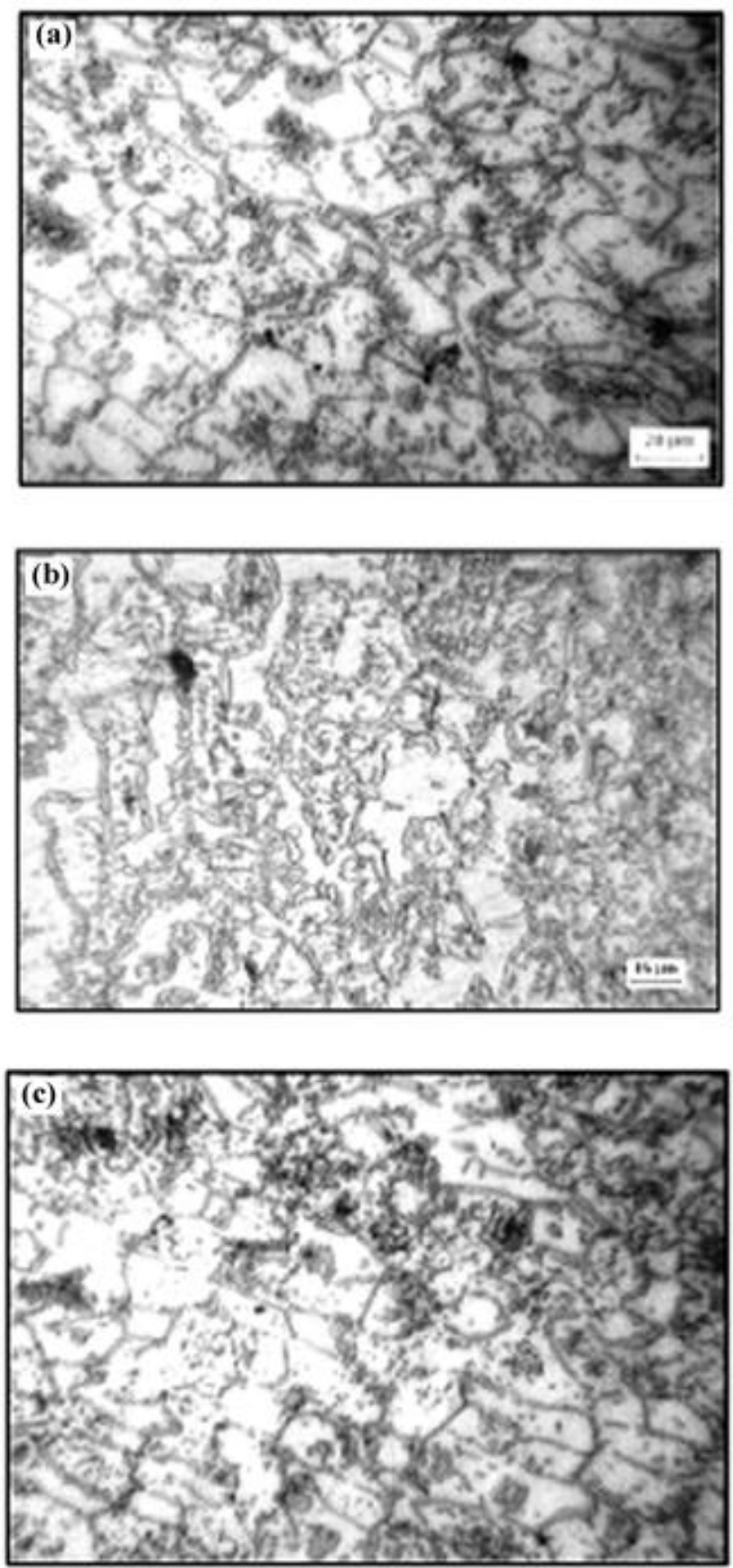

Figure 5. Optical micrographs of $\mathrm{Fe}-19 \cdot 2 \mathrm{Al}-3 \cdot 3 \mathrm{C}-0 \cdot 07 \mathrm{Ce}$ alloy in the (a) rolling plane, (b) long transverse, and (c) short transverse directions. 
The contiguity of the bulky carbide phases is reported in table 2. The results show that the second phase carbides in the samples, $\mathrm{Fe}-18 \cdot 5 \mathrm{Al}-3 \cdot 6 \mathrm{C}$ and $\mathrm{Fe}-19 \cdot 2 \mathrm{Al}-3 \cdot 3 \mathrm{C}-$ $0.07 \mathrm{Ce}$, are more contiguous and proximate than the carbides in $\mathrm{Fe}-20 \cdot 0 \mathrm{Al}-2 \cdot 0 \mathrm{C}$. This is due to the higher amount of carbon in $\mathrm{Fe}-18 \cdot 5 \mathrm{Al}-3.6 \mathrm{C}$ and $\mathrm{Fe}-19 \cdot 2 \mathrm{Al}-3 \cdot 3 \mathrm{C}-$ $0 \cdot 07 \mathrm{Ce}$. Moreover, in case of the $\mathrm{Ce}$ added sample, $\mathrm{Fe}-$
$19 \cdot 2 \mathrm{Al}-3 \cdot 3 \mathrm{C}-0 \cdot 07 \mathrm{Ce}$, the role played by $\mathrm{Ce}$ in producing a finer and uniform distribution of carbides can be the reason for the observed higher contiguity in the $\mathrm{Fe}$ 19.2Al-3.3C-0.07Ce sample.

It is well known that $\mathrm{Ce}$ is generally added in cast iron to act both as an inoculant and as a nodulariser (Kay et al 1975). Ce ties up the trace elements such as $\mathrm{Pb}, \mathrm{As}, \mathrm{Bi}$,
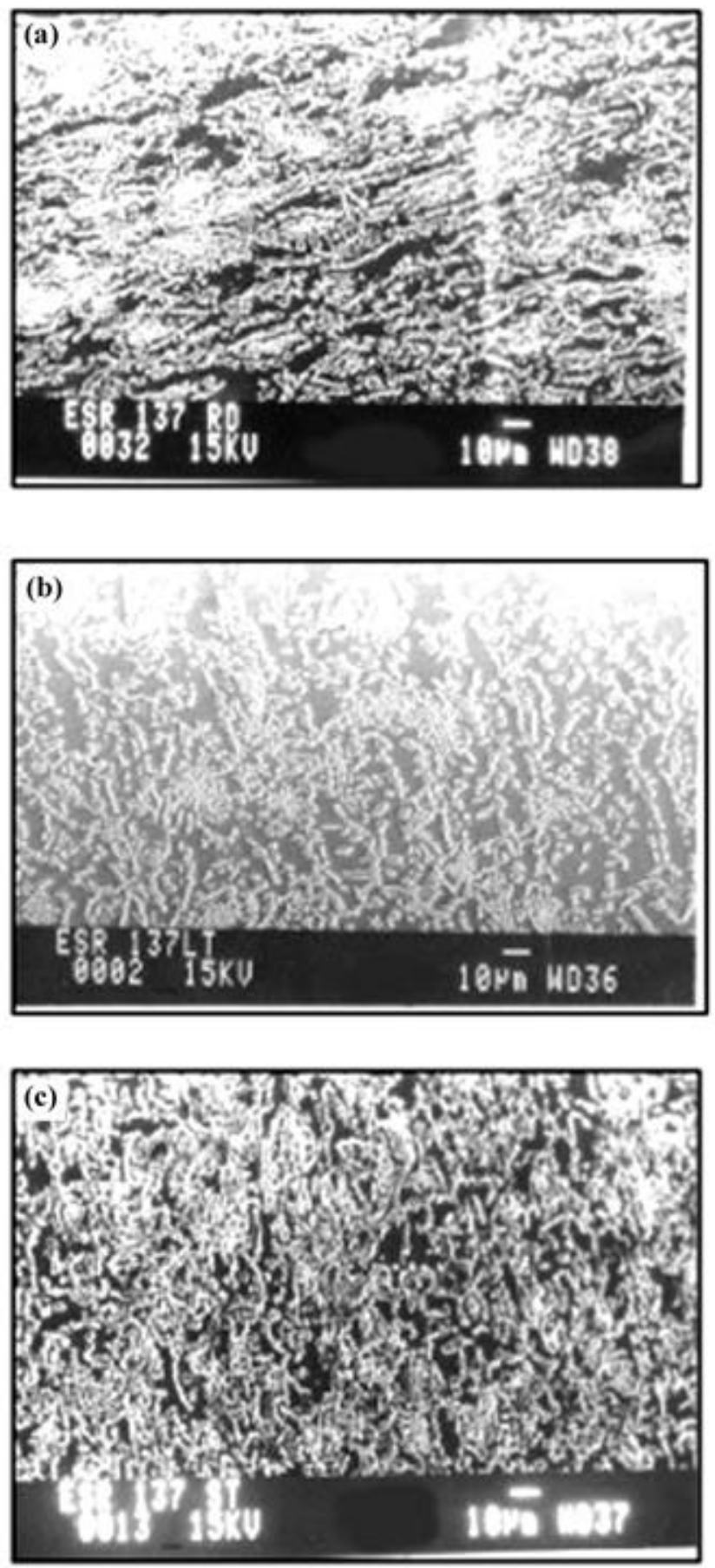

Figure 6. Scanning electron micrographs of $\mathrm{Fe}-19 \cdot 2 \mathrm{Al}-$ $3 \cdot 3 \mathrm{C}-0.07 \mathrm{Ce}$ alloy in the (a) rolling plane, (b) long transverse, and (c) short transverse directions.
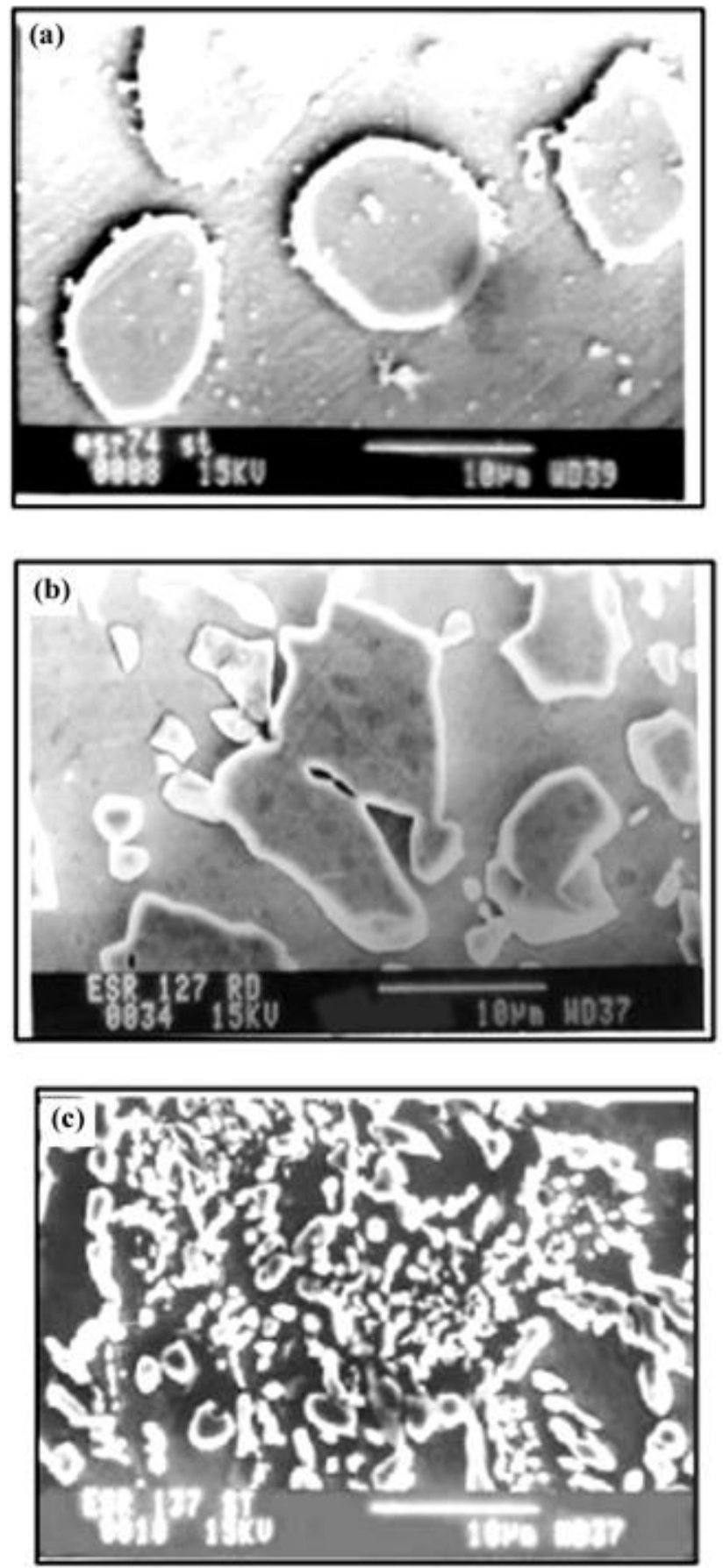

Figure 7. Scanning electron micrographs of (a) $\mathrm{Fe}-20 \cdot 0 \mathrm{Al}-$ 2.0C, (b) Fe-18.5Al-3.6C and (c) Fe-19.2Al-3.3C-0.07Ce observed at higher magnification. 
Table 1. Grain size and mean volume fraction $\left(\bar{V}_{\mathrm{V}}\right)$ of the bulky carbides distributed in the rolling plane of samples $\mathrm{Fe}-20 \cdot 0 \mathrm{Al}-2 \cdot 0 \mathrm{C}, \mathrm{Fe}-18 \cdot 5 \mathrm{Al}-3 \cdot 6 \mathrm{C}$ and $\mathrm{Fe}-19 \cdot 2 \mathrm{Al}-3 \cdot 3 \mathrm{C}-0 \cdot 07 \mathrm{Ce}$ samples.

\begin{tabular}{lccccc}
\hline & \multicolumn{2}{c}{ Grain size } & & \multicolumn{2}{c}{$\begin{array}{c}\text { Volume fraction of } \\
\text { bulky carbides }\end{array}$} \\
\cline { 2 - 3 } \cline { 5 - 6 } Composition & $\begin{array}{c}\text { Mean } \\
(\mu \mathrm{m})\end{array}$ & $\begin{array}{c}95 \% \text { confidence } \\
\text { interval }\end{array}$ & & Mean & $\begin{array}{c}95 \% \text { confidence } \\
\text { interval }\end{array}$ \\
\hline $\mathrm{Fe}-20 \cdot 0 \mathrm{Al}-2 \cdot 0 \mathrm{C}$ & $480 \cdot 48$ & $54 \cdot 10$ & & 0.20 & 0.0353 \\
$\mathrm{Fe}-18 \cdot 5 \mathrm{Al}-3 \cdot 6 \mathrm{C}$ & 574.91 & $85 \cdot 90$ & & 0.33 & 0.0406 \\
$\mathrm{Fe}-19 \cdot 2 \mathrm{Al}-3 \cdot 3 \mathrm{C}-0 \cdot 07 \mathrm{Ce}$ & - & - & & 0.35 & 0.0457 \\
\hline
\end{tabular}

Table 2. Exploded surface area per unit volume and contiguity of the carbides distributed in the rolling plane of $\mathrm{Fe}-20 \cdot 0 \mathrm{Al}-2 \cdot 0 \mathrm{C}, \mathrm{Fe}-18 \cdot 5 \mathrm{Al}-3 \cdot 6 \mathrm{C}$ and $\mathrm{Fe}-19 \cdot 2 \mathrm{Al}-3 \cdot 3 \mathrm{C}-0 \cdot 07 \mathrm{Ce}$ samples.

\begin{tabular}{lccccc}
\hline & \multicolumn{2}{c}{$\begin{array}{c}\text { Exploded surface area per } \\
\text { unit volume }\end{array}$} & & \multicolumn{2}{c}{ Contiguity } \\
\cline { 2 - 3 } \cline { 5 - 6 } Composition & $\begin{array}{c}\text { Mean } \\
\left(\mu \mathrm{m}^{-1}\right)\end{array}$ & $\begin{array}{c}95 \% \text { confidence } \\
\text { interval }\end{array}$ & & Mean & $\begin{array}{c}95 \% \text { confidence } \\
\text { interval }\end{array}$ \\
\hline $\mathrm{Fe}-20 \cdot 0 \mathrm{Al}-2 \cdot 0 \mathrm{C}$ & $0 \cdot 230$ & 0.0364 & & 0.065 & 0.0201 \\
$\mathrm{Fe}-18 \cdot 5 \mathrm{Al}-3 \cdot 6 \mathrm{C}$ & $0 \cdot 247$ & 0.0146 & & 0.160 & 0.0317 \\
$\mathrm{Fe}-19 \cdot 2 \mathrm{Al}-3 \cdot 3 \mathrm{C}-0 \cdot 07 \mathrm{Ce}$ & $0 \cdot 237$ & 0.0146 & & 0.114 & 0.0344 \\
\hline
\end{tabular}

$\mathrm{Sb}, \mathrm{Sn}, \mathrm{Al}, \mathrm{Cd}$ and $\mathrm{Ti}$, which have a negative influence on the structure of graphite. Additionally, Ce reacts with both dissolved oxygen and sulphur in the cast iron melt and forms sulphide or oxide inclusions which are of the type $X_{2} Y_{3}$ and $X Y_{2}$, where $X$ is $C e$ and $Y$ is either sulphur or oxygen. These inclusions act as nuclei for the nucleation of graphite and hence reduce the undercooling necessary to initiate eutectic solidification. This increase in the nucleation rate of the graphite nodules in the ductile cast iron results in the formation of graphite nodules. This eventually produces the so-called ductile cast iron. The morphology of graphite is changed from flakes to nodules in case of Ce alloyed cast iron (Kay et al 1975) because Ce chemically combines with sulphur and oxygen. Based on this well known effect, it is reasonable to conclude a similar effect for $\mathrm{Ce}$ in the case of carbonalloyed iron aluminides.

\section{Conclusions}

Microstructural observations indicated that the alloys, $\mathrm{Fe}-18 \cdot 5 \mathrm{Al}-3 \cdot 6 \mathrm{C}, \mathrm{Fe}-20 \cdot 0 \mathrm{Al}-2 \cdot 0 \mathrm{C}$ and $\mathrm{Fe}-19 \cdot 2 \mathrm{Al}-3 \cdot 3 \mathrm{C}-$ $0.07 \mathrm{Ce}$ (in at \%), exhibited a typical two-phase structure consisting of carbides dispersed in a iron aluminide matrix. The matrix contained recrystallized grains. In the case of the alloys, $\mathrm{Fe}-18 \cdot 5 \mathrm{Al}-3 \cdot 6 \mathrm{C}$ and $\mathrm{Fe}-20 \cdot 0 \mathrm{Al}-2 \cdot 0 \mathrm{C}$, larger bulky carbides were equally distributed throughout the matrix with many smaller precipitates interspersed in between. However, in case of the $\mathrm{Ce}$ added alloy, $\mathrm{Fe}-$ $19 \cdot 2 \mathrm{Al}-3 \cdot 3 \mathrm{C}-0 \cdot 07 \mathrm{Ce}$, the carbide grain sizes were much finer and they were more uniformly distributed throughout the matrix. Addition of Ce affected morphology and size of the carbides. Stereological analysis, carried out on the rolling plane of the alloys confirmed that the alloys possessing higher carbon content, i.e. $\mathrm{Fe}-18 \cdot 5 \mathrm{Al}-3 \cdot 6 \mathrm{C}$ and $\mathrm{Fe}-19 \cdot 2 \mathrm{Al}-3 \cdot 3 \mathrm{C}-0 \cdot 07 \mathrm{Ce}$, exhibited higher volume fraction of carbide and higher exploded surface area per unit volume, when compared to the lower carbon alloy, Fe20.0Al-2.0C. Contiguity studies revealed that the second phase carbide phases in the samples, Fe-18.5Al-3.6C and $\mathrm{Fe}-19 \cdot 2 \mathrm{Al}-3 \cdot 3 \mathrm{C}-0 \cdot 07 \mathrm{Ce}$, were more contiguous and proximate than the carbides in $\mathrm{Fe}-20 \cdot 0 \mathrm{Al}-2 \cdot 0 \mathrm{C}$. The effect of $\mathrm{Ce}$ addition on the modification of the carbide structure has been explained based on the well-known effect of $\mathrm{Ce}$ addition in modifying the carbide/graphite morphology in cast irons.

\section{Acknowledgement}

The authors acknowledge financial support by the Defence Research and Development Organization (DRDO), Ministry of Defence, Government of India.

\section{References}

Balasubramaniam R 1996 Scr. Mater. 34127

Balasubramaniam R 1997 J. Alloys Comp. 253-254 148

Baligidad R G and Radhakrishna A 2000 Mater. Sci. Engg. A287 17

Baligidad R G, Prakash U, Ramakrishna Rao V, Rao P K and Ballal N B 1994 Iron and Steel Making 21324

Baligidad R G, Prakash U, Radhakrishna A and Ramakrishna Rao V 1997a Scr. Mater. 36105 
Baligidad R G, Prakash U, Radhakrishna A and Ramakrishna Rao V 1997b Scr. Mater. 36667

Kay D A R, Lu W K and McLean A 1975 Rare earth-oxygensulfur reactions in molten steel, in Sulfide inclusions in steel, Proceedings of an international symposium (eds) J J deBarbadillo and E Snape (Metals Park, USA: American Society for Metals) pp 23-43

Laha T, Tewari A, Balasubramaniam R, Mungole M N and Baligidad R G 2004 Met. Mater. Trans. A35 1789

Lin D, Shan A and Li D 1994 Scr. Metall. Mater. 311455

Liu C T and Kumar K S 1993 J. Metals 4538

Liu C T, Stiegler J O and Fores F H 1990a Ordered intermetallics, in Metals handbook (Metals Park, USA: American Society for Metals) 10 ed., Vol. 2, pp 913-943
Liu C T, McKamey C G and Lee E H 1990b Scr. Metall. 24385

Liu C T, McKamey C G and Lee E H 1996 Scr. Metall. 23 875

McKamey C G and Liu C T 1992 Scr. Metall. Mater. 24119

McKamey C G and Pierce D H 1993 Scr. Metall. Mater. 281173

Parvathavarthini N, Prakash U and Dayal R K 2002 Intermetallics 10329

Prakash U and Sauthoff G 2001 Scr. Mater. 4473

Sen M and Balasubramaniam R 2000 Scr. Mater. 44619

Underwood E 1970 Quantitative stereology (New York: Addison-Wesley Publishing Company) pp 25-103

Yangshan S, Zhengjun Y S, Zhonghua Z and Haibo H 1995 Scr. Metall. Mater. 33811

Zhu Y F, Liu C T and Chen C H 1996 Scr. Mater. 351435 